\title{
Paleogeomorphic Influence on Facies Characteristics of Braided Delta and Reservoir Prediction-An Example from $L$ oilfield in Bohai Bay Basin
}

\author{
Longtao Cui, Xinwu Liao, Liye Zhou, Cheng Guo, Lan Zhang \\ Tianjin Branch of CNOOC Ltd., Tianjin, China \\ Email: cuilt2@cnooc.com.cn
}

How to cite this paper: Cui, L. T., Liao, X. W., Zhou, L. Y., Guo, C., \& Zhang, L. (2019). Paleogeomorphic Influence on Facies Characteristics of Braided Delta and Reservoir Prediction-An Example from L oilfield in Bohai Bay Basin. Journal of Geoscience and Environment Protection, 7, 195-205.

https://doi.org/10.4236/gep.2019.78014

Received: July 4, 2019

Accepted: August 20, 2019

Published: August 23, 2019

Copyright $\odot 2019$ by author(s) and Scientific Research Publishing Inc. This work is licensed under the Creative Commons Attribution International License (CC BY 4.0).

http://creativecommons.org/licenses/by/4.0/

\section{(c) (i) Open Access}

\begin{abstract}
Five wells of L oilfield in Bohai bay basin have drilled 10 - 15 meters thick oil layer in the Paleogene delta. Due to the deep-buried reservoir and the poor seismic performance, it is difficult to identify the reservoir genesis, and predict reservoir distribution. By analyzing core, well logging and seismic data, a stable mudstone section is selected as the correlation marker to establish a stratigraphic framework. The paleogeomorphology is reconstructed after decompaction correction and paleobathymetric analysis. Based on the differences of paleotopography and sedimentary facies, the study area mainly develops two delta systems: low gradient coarse-grain delta system and steep gradient delta-turbidite system. The favorable reservoir of low gradient coarse-grain delta, which is thick and has good lateral connectivity, mainly locates in the delta front. The favorable reservoir of steep gradient delta-turbidite system locates in the delta front and turbidite facies, and the delta front deposits are thin and have poor lateral connectivity. The boundary of delta front is first depicted on the basis of paleotopography. In combination with reservoir architecture and forward modeling analysis, the seismic attribute is then optimized to predict the distribution of favorable reservoir. Using this method, several sets of oil-bearing sandbodies have been drilled in $\mathrm{L}$ oilfield, and the prediction accuracy of reservoir distribution is proved to be high. This study demonstrates that the paleogeomorphology plays an important role in controlling the genesis and distribution of the delta reservoir and provides reference for the reservoir prediction in similar oilfields.
\end{abstract}

\section{Keywords}

Slope Zone, Braided Delta, Reservoir Prediction, Forward Modeling 


\section{Introduction}

The L oilfield is a delta reservoir with proven recoverable oil reserve of nearly 100 million tons. The main oil-bearing strata are the group I of S3 formation, Paleogene. Five wells have drilled thick reservoir (10 - 15 meters) under the group I, with newly discovered reserve of nearly 10 million tons, and it is one of the targets with great potential. The reservoir is a set of foreset feature in the seismic profile, which has the following problems in oilfield development: 1) The reservoir is deeply buried (2500 meters) and the resolution of seismic data is low, which makes it difficult to predict reservoir distribution; 2) The strata in the slope background are foreset deposit, which makes it difficult to divide and predict the reservoirs in different periods; 3 ) The difference of delta facies leads to a great change in the seismic response of the reservoir (Zhang et al., 2015). The study of delta characteristics and slope is of great significance for predicting reservoir distribution. Lemons discussed the characteristics of sedimentary systems under the influence of different gradient slopes in a faulted basin (Lemons \& Chan, 1999). Galloway analyzed the control effect of continental shelf margin slope on the sedimentary system (Galloway, 1975; Galloway \& Hobday, 1983). Lin et al. (2004) studied the development and distribution of the sedimentary system under the control of the fault slope of lacustrine basin, and emphasized the control of the slope on the accommodating space, sequence, system domain and sand body distribution. Wang et al. (2003) studied the control of slope on sedimentary distribution in the depression lake basin. Some scholars applied seismic inversion technology, seismic slicing and other reservoir prediction methods to predict the reservoir distribution in the study area (Wang et al., 2002). The studies above have achieved certain effects in studying the sedimentary characteristics and distribution patterns of the delta. However, how to accurately depict the distribution of the delta reservoir on the slope needs further study. In this paper, the stratigraphic framework is firstly established by analyzing core, well logging and seismic data. Secondly, the paleogeomorphology is restored to study its control on distribution of reservoir. The original strata thickness is restored and the paleo-water depth is corrected to reconstruct the paleogeomorphology. Finally, on the basis of slope characterization and forward modeling experiments, seismic attributes are optimized to predict the distribution of favorable reservoir. This study proves that the slope plays an important role in controlling the formation and distribution of delta reservoirs and provides reference for reservoir prediction of similar oilfields.

\section{Geological Setting}

L oilfield is located in Laizhou bay sag in Bohai bay, China. It is a semi-anticlinal structure attached to faults. The main oil-bearing strata are the group I of S3 formation, Paleogene with a buried depth of $2110 \mathrm{~m}-2764 \mathrm{~m}$. In this study, the target strata are the group II of S3 formation. The provenance is provided by the ancient Yellow River system in the western Kendong uplift, forming a braided 
delta system with a huge area (Figure 1).

\section{Stratigraphic Framework}

Stratigraphic division and correlation are the basis for the restoration of ancient topography and the study of sedimentary types and distribution. Galloway (1975) believes that stable oil shale segments or mudstones formed during the MFS can serve as a marker of stratigraphic correlation. In this paper, the stable mudstone segment (bottom Q1) is selected as the marker layer to analyze the characteristics of strata, and the stratigraphic units are divided and isochronal stratigraphic framework is established.

\subsection{Interface Recognition and Sequence Division}

A maximum flooding surface (Mfs) and a sequence boundary (SB) are identified in S3 formation (Figure 2). A set of foreset strata developed under the sequence boundary. The Mfs is the bottom boundary of the foreset strata and below which is the parallel and sub-parallel reflection strata, showing completely different sedimentary environments (Figure 2). According to the characteristics of sedimentary facies, the formation is divided into Lowstand System Tract (corresponding to group I) and Highstand System Tract (corresponding to group II to the bottom). Six fourth-order sequences (Q1-Q6) are identified in HST, and one fourth-order sequence (Q7) is identified in LST.

\subsection{Stratigraphic Evolution}

It reflects the process of progradation (Q1-Q6) from the maximum flooding surface (bottom of Q1), and then the erosion occurs, followed by accretion and regression (Q7) (Figure 2). According to the lateral analysis of strata, the delta front, lake and turbidite rocks are deposited successively from well 1 to well 4 . As the delta plain is later eroded, the strata thickness showed a trend of "from thick to thin", in which the delta front is thicker (Q4 cycle in Figure 2). Turbidite is formed in the slope of delta front where the terrain gradient changes. Vertical analysis of strata shows that the study area mainly locates in the delta front during Q1-Q6 period. As the slope moves to the center of the lake basin, the delta front continuously progradates to the center of the lake basin, forming overlapping delta lobes. At the end of Q6 deposition, the seismic profile shows a foreset feature. In the Q7 period, the initial datum level rises, the slope gradually disappears.

\section{Paleotopography Restoration and Slope Characterization}

The characteristics of basin margins and paleotopography have significant control over the sedimentary genesis and distribution characteristics, so the study on the restoration of paleoslope at the edge of lake basin and the control of sedimentation is currently a hot area in the analysis of oil-bearing basins, and proved to be an effective method for oil and gas prediction (Deptuck et al., 2007; Posamentier \& Kolla, 2003; Plint \& Wadsworth, 2003). 


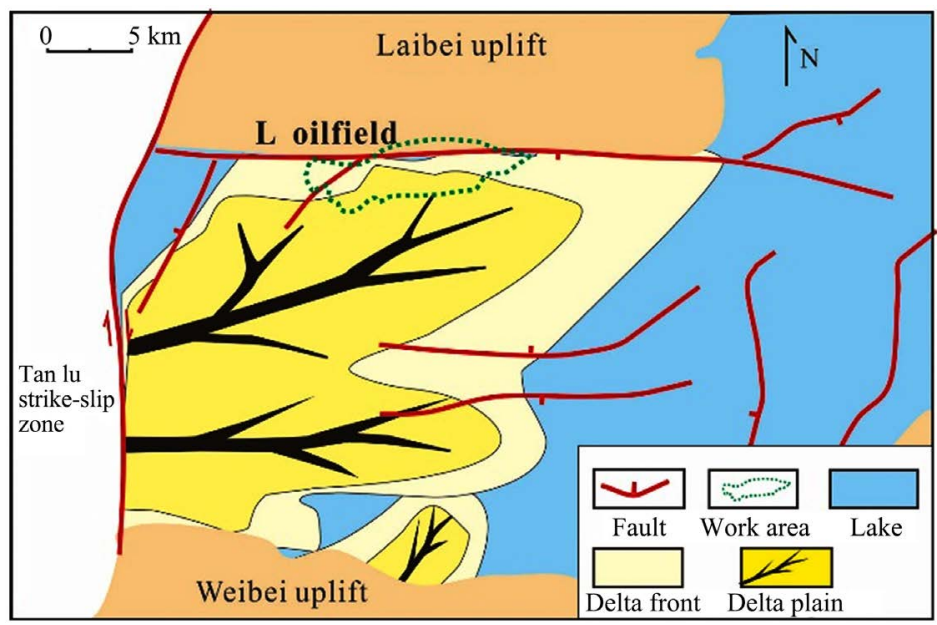

Figure 1 . The study area of X oilfield and the facies map of the S3 formation.
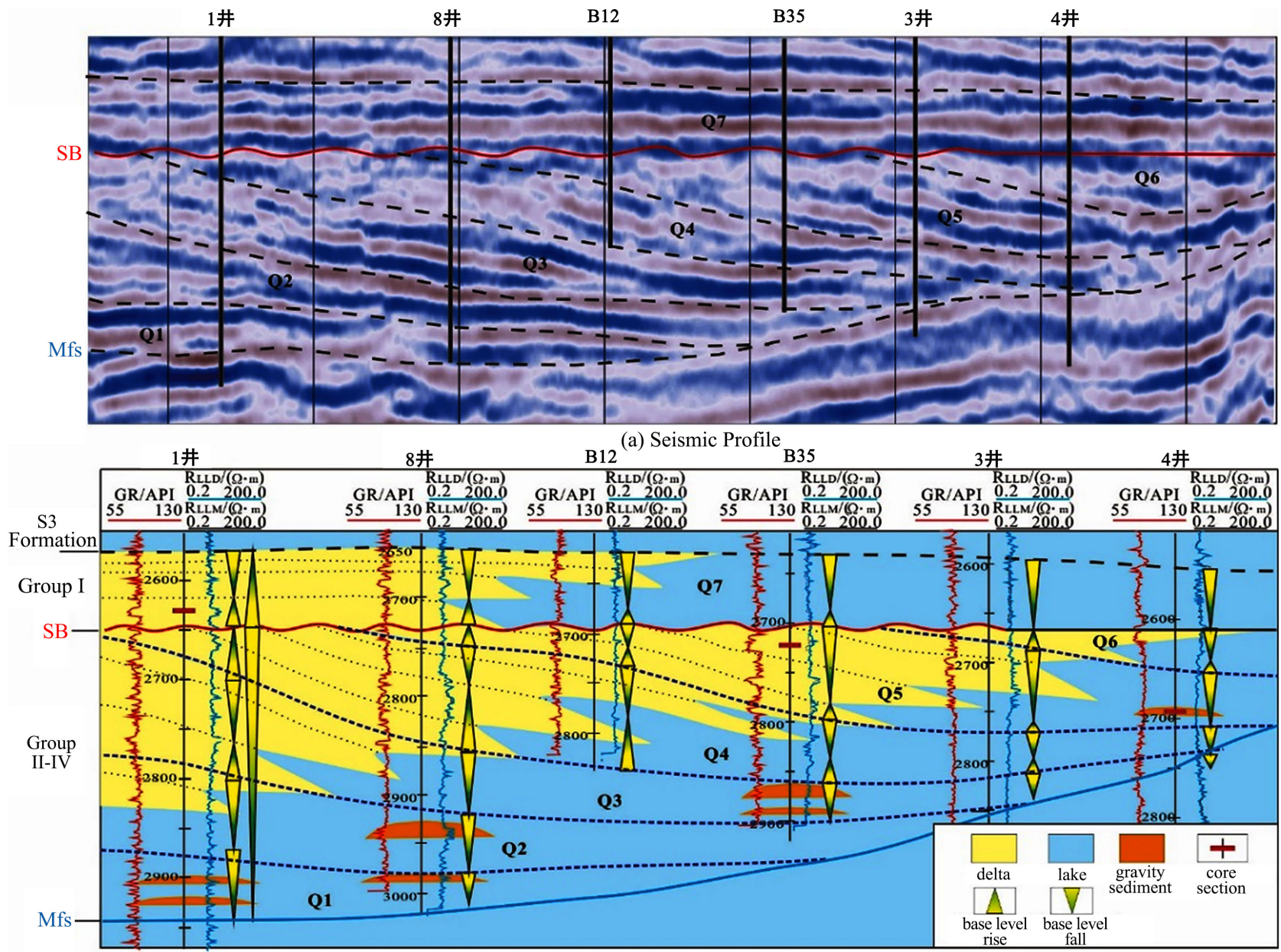

(b) Stratigraphic Framework

Figure 2. Interface recognition and sequence division.

Paleotopography restoration mainly includes erosion correction, formation compaction correction and paleo-depth correction (Cui et al., 2013; Cui et al., 2015). Taking the fourth-order sequence as a unit, the initial sedimentary thick- 
ness of the target layer was restored and the paleo-bathymetric correction is carried out, respectively restoring the pre-sedimentary topography of the paleogene Q1-Q7 period in L oilfield. The results show that $\mathrm{L}$ oilfield is dominated by slope on paleotopographic map. As the accommodating space near the slope is changeable, the sedimentary facies and sedimentary thickness are often abrupt, and the isolines in the slope area are relatively dense. Therefore, the range of slope zones in the Q1-Q7 period can be depicted on the paleotopographic map according to the contour density.

Taking Q4, Q5 and Q7 periods as examples, the topography and evolution characteristics of the study area are depicted. In the Q4 period, the study area is controlled by a single slope. The width of slope is about 3.5 to $4.5 \mathrm{~km}$, and $0.25^{\circ}$ to $0.33^{\circ}$ (Figure $3 \mathrm{left}$ ); the center of the lake basin is located in the southeast, roughly east of well 7. In the Q5 period, the study area was still controlled by a single slope. The source caused the slope migrates to the well B10-B12. Slopes eastward migration of about $4.0 \mathrm{~km}$, the width is about 3.0 to $4.0 \mathrm{~km}$, sloping slightly slower, $0.20^{\circ}$ to $0.22^{\circ}$ (Figure 3 , right). The center of the lake basin moves eastward to the east of well 4 . In the Q7 period, the slope gradient is less than $0.1^{\circ}$, and the slope has little effect on topography and sediment distribution.

\section{Sedimentary Characteristics}

The change of Lake Surface affects the change of Lake Shoreline because of the difference of slope gradient and length. There are also significant differences in source supply rate and grain size, which further restrict the size of the accommodating space and the distribution of the sedimentary system (Posamentier \& Allen, 1993). The braided delta front is mainly developed in the S3 formation. Through core observation and log data analysis, combined with the study of slope characteristics, there are two main sedimentary types in the study area: braided delta system with gentle slope and braided delta-gravity flow system with steep slope, respectively as follows:

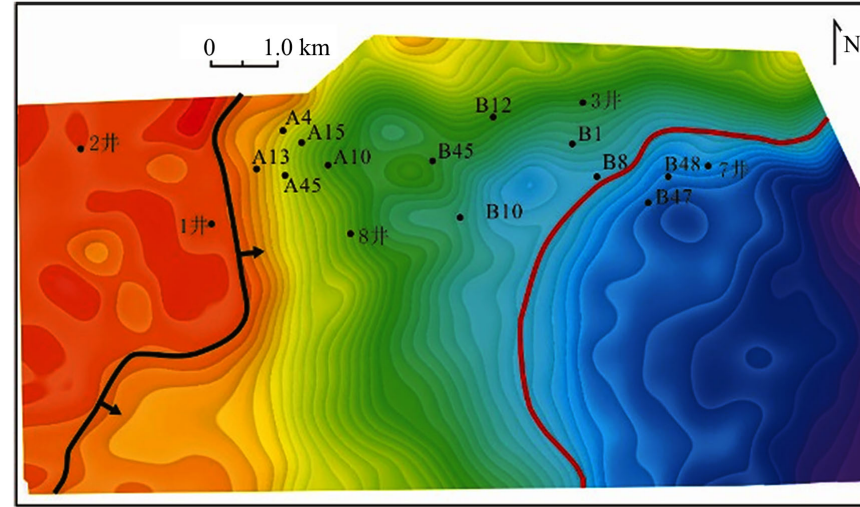

S. Slope Break

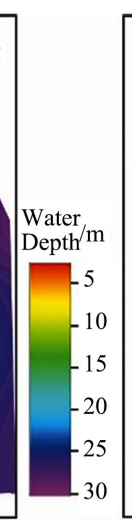

Slope Toe

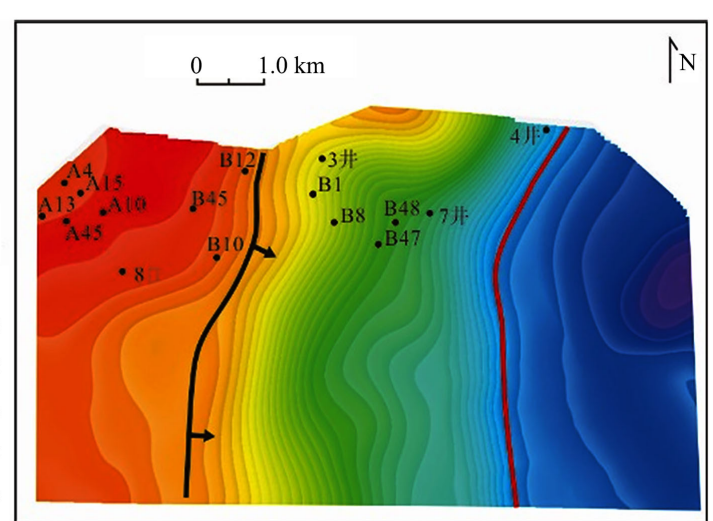

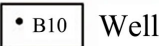

Figure 3. Paleotopography in Q4 period (left) and Q5 period (right). 


\subsection{Braided Delta-Gravity Flow System with Steep Slope}

During the Q1-Q6 period, the slope of the sedimentary system is relatively steep (greater than $0.2^{\circ}$ ), and the slope has a significant control effect on sedimentation. The sedimentary system of the study area is mainly composed of delta front and gravity sediment, including five kinds of sedimentary microfacies, namely underwater distributary channel, estuary bar, sheet sand, and turbidite. The accommodating space during this period is large, resulting in less swinging of the underwater distributary channel and isolated single channel deposition with a thickness of $2-5 \mathrm{~m}$ (Figure 4(c)); the estuary bar is an important reservoir in the study area, and the sand body is made of gray fine sandstone. The wavy staggered bedding and intra-layer deformation structure is developed. Turbidite mainly develops fine sandstone and Bouma sequence, with thickness $10 \mathrm{~cm}$ to tens of meters (Figure 4(b)).

The delta front is the concentrated development section of steep slope reservoir. The reservoirs such as the underwater distributary channel and the estuary bar have large reservoir thickness $(2-5 \mathrm{~m})$ and the reservoir properties are good (the permeability is greater than $100 \mathrm{mD}$ ); the sheet sand is thin $(1-2 \mathrm{~m})$, reservoir properties are poor (permeability is less than $100 \mathrm{mD}$ ) and lateral connectivity is poor. Turbidity deposition is one of the dominant reservoirs in the steep slope delta, with reservoir thicknesses ranging from $10 \mathrm{~cm}$ to tens of meters and poor reservoir properties (permeability $50-100 \mathrm{mD}$ ).

\subsection{Braided Delta System with Gentle Slope}

During the Q7 period, the slope of the study area was relatively slow (less than $0.1^{\circ}$ ). The study area is dominated by the developmental delta front, which mainly includes three kinds of sedimentary microfacies, namely, underwater distributary channels and inter-channel sediments. Due to the small accommodating space during this period, the delta frontal underwater channel oscillates laterally, and the multi-stage vertical cutting is superposed. The single-stage river channel has a thickness of $1-4$ meters and the stacked thickness can reach several tens of meters. The lithology is dominated by light gray medium coarse sandstone, see the bottom flushing surface, wedge-shaped cross-layering, etc. (Figure 4(a)). The lake shoreline has a large range of advance and retreat, which leads to the formation of a thin layer of mudstone and a sudden contact with the river channel during the flooding period. The sheet sand is an interbedded layer of gray fine sandstone and mudstone, which can be seen in a blocky or wavy layer.

The main reservoir of the gentle slope-shaped braided delta is the delta front. The subaqueous distributary channel has a large reservoir thickness (up to several tens of meters of stacked river channels), good physical properties (permeability can be greater than $500 \mathrm{mD}$ ), and good lateral connectivity. The distal end of the delta front is dominated by the development of the sheet sand, the reservoir thickness is thin $(1-2 \mathrm{~m})$, and the physical properties are good (the permeability is less than $100-300 \mathrm{mD}$ ). 


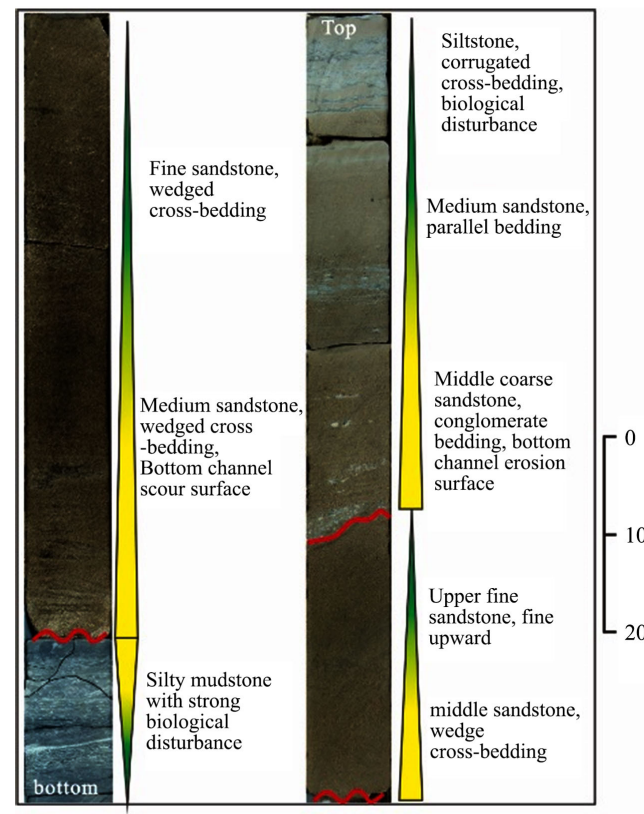

(a) low gradient coarse-grain delta

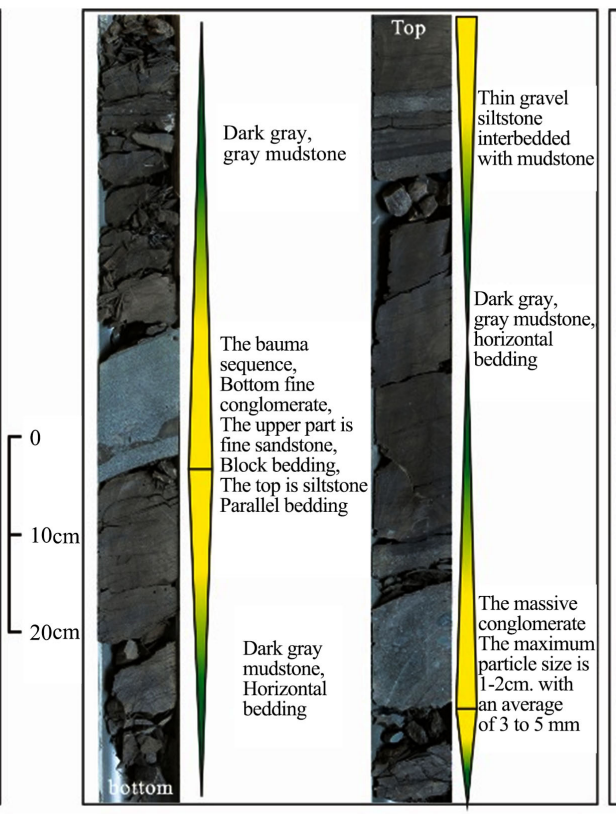

(b) steep gradient turbidite deposit

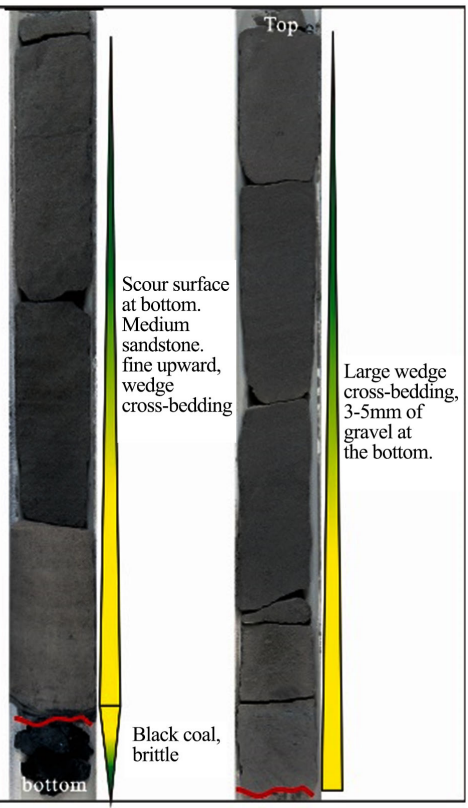

(c) steep gradient delta

Figure 4. Core characteristics of S3 section in L oilfield in well 1 of Q7 period showing (a) coring section of well 4 of Q5 period; (b) coring section of well B35 of Q5 period; (c) coring section showing steep gradient delta.

\section{Prediction of Main Reservoir in Delta Front}

In order to accurately predict the main reservoir of the delta front, the fourth-order sequence is used as a unit to describe the delta front range according to the ancient topography. Combined with forward modeling, the response characteristics of the reservoir structure of the delta front in seismic data are studied.

The change in the deposition rate of the delta front causes the difference in sediment thickness to produce a change in the topographic gradient. The sedimentary slope developed in the study area begins at the junction of the delta front and the delta plain, and the slope ends at the delta front. The slope is relatively dense on the topographical contour, and the thickness of the strata is reduced at the foot of the slope. Therefore, the slope of the Q1-Q7 period is the delta front based on the ancient topographic map.

\subsection{Forward Modeling}

The seismic profile of the S3 formation is characterized by a set of high-angle S-type anterior reflection features. The research focuses on the analysis of the pre-strata to determine the relationship between reservoirs and seismic attributes, and then to study the seismic response characteristics of different reservoirs. Combined with the characteristics of the delta front sandstone and mudstone, the geological model is designed for forward modeling. The main reservoir of the study area is concentrated at the proximal end of the delta front. The stratigraphic structure is a superposed subaqueous distributary channel and mouth bar. The reservoir thickness is large (the maximum reservoir thickness is 
$30 \mathrm{~m}$ ) and the shale content is low. The end strata structure is mainly composed of sheet sand. The thickness of the reservoir is gradually reduced and the shale content is gradually increased. The sandstone is characterized by low density $\left(2.3 \mathrm{~g} / \mathrm{cm}^{3}\right)$ and high velocity $(3200 \mathrm{~m} / \mathrm{s})$; the mudstone is characterized by high density $\left(2.5 \mathrm{~g} / \mathrm{cm}^{3}\right)$ and low velocity $(3000 \mathrm{~m} / \mathrm{s})$.

The forward results show that the sandstone enrichment area of the delta front is dominated by weak amplitude, and the mudstone enrichment area is mainly characterized by strong amplitude. As the mud content increases, the seismic amplitude of the delta front increases. The relevance between sandstone thickness and various amplitude properties is analyzed. It is found that the relevance between sandstone thickness and RMS amplitude property is above $70 \%$. Therefore, within the delta front, the RMS attribute is used to predict the planar distribution characteristics of the dominant reservoir.

\subsection{Reservoir Characterization under the Boundary of Slope}

Under the constraint of the delta front boundary, combined with the RMS amplitude attribute of the Q1-Q7 period of the S3 formation, the distribution of the sand body is finely characterized (Figure 5 ). The research indicates that the provenance from the western part of the L oilfield is sufficient, and the development type is mainly the delta front. The multi-period leaf body deposited in the eastward advances eastward from the Q1 period, and the delta advances the furthest in the Q6 period. During the Q7 period, the lake level begins to rise and the delta begins to retreat. Taking the Q4 period as an example, the distribution characteristics of the delta front are analyzed. In the Q4 period, the L oil field is controlled by steep slopes, and the underwater river channel with a certain thickness and wide distribution is formed by the slope. The river channel is distributed in strips, and the width of the river channel is about $100-300 \mathrm{~m}$. The underwater distributary channel extends a distance of $4-5 \mathrm{~km}$, and the river sand body in the direction of the source is in good continuity (such as the A13, A45, A10 wells in the same river channel), which is the reservoir distribution with large sandstone thickness and good reservoir properties. The sandstone at the edge of the river is thin and the muddy content is relatively high; the area outside the delta is dominated by mudstone, and the sandstone reservoir is basically not developed.

\section{Prediction Accuracy and Application in Oilfield Development}

The accuracy of the reservoir characterization method is tested from two aspects: the accuracy of the reservoir boundary and thickness. Taking the Q4 deposition period as an example, through the well drilling analysis, the reservoir distribution is consistent with the depicted delta boundary, and the reservoir thickness within the boundary is characterized accurately. For example, the main part of the river is weak in amplitude, the reservoir is thicker (Well A10 and B45 in Figure $5 \&$ Table 1), and the reservoir at the edge of the river is thinned (Well 


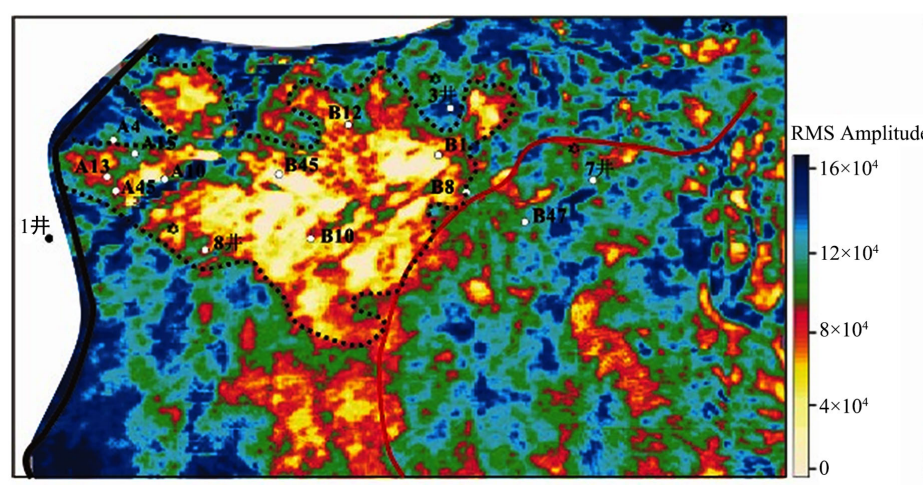

(a) the seismic attribute map of Q4 period

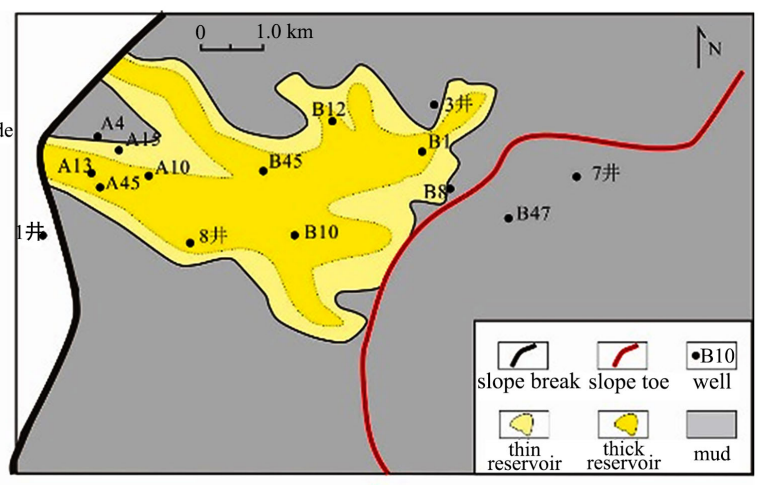

(b) the reservior distribution map of Q4 period

Figure 5. Q4 period in L oilfield: (a) Seismic attribute map; (b) Reservoir distribution map.

Table 1. The relevance between sandstone thickness and RMS amplitude property.

\begin{tabular}{cccccccccccc}
\hline well & B45 & B12 & B8 & 3 & A13 & A4 & A15 & A10 & A45 & B10 & B1 \\
\hline $\begin{array}{c}\text { Sandstone } \\
\begin{array}{c}\text { Thickness } \\
\text { /meter }\end{array}\end{array}$ & 10 & 6 & 1 & 0.5 & 8 & 1 & 2 & 7 & 11 & 9 & 8 \\
$\begin{array}{c}\text { RMS } \\
\text { amplitude }\end{array}$ & 40,000 & 50,000 & 90,000 & 130,000 & 70,000 & 110,000 & 90,000 & 40,000 & 60,000 & 35,000 & 36,000 \\
\hline
\end{tabular}

A15 and B1 in Figure 5 \& Table 1); and outside the range, mudstone is the main source, and the reservoir is basically not developed. Combined with the characteristics of the ancient topography and the reservoir distribution model, the range of the main reservoirs in each period is depicted in the delta front of the Q3-Q7 period in the S3 Formation. Among them, Well B10 and B8 have drilled 10 - $20 \mathrm{~m}$ thick oil layer in the delta front of Q4 period and Q5 period respectively.

Due to the gentle terrain of the gentle slope-shaped delta, the lake is washed repeatedly, the reservoir has good lateral connectivity, low mud content and good reservoir properties (permeability can be greater than $500 \mathrm{mD}$ ), which is a favorable area for production well deployment. The development wells also show that this type of reservoir has a higher daily oil production (average daily oil production of $80 \mathrm{~m}^{3}$ per day), which is the main oil production horizon of the oilfield. Reservoirs such as the diversion channel with steep slope-type delta front have poor lateral connectivity and good reservoir properties (permeability is about $100 \mathrm{mD}$ ). The development well shows that the lateral variation of this type of reservoir is large, and the average daily oil production is about $40 \mathrm{~m}^{3}$ per day, which is the secondary oil production horizon of the oilfield.

\section{Conclusion}

Seven fourth-order sequences (q1-q7) were identified in the S3 formation, and show that the study area is dominated by slope mainly of low gradient coarse-grain delta system and steep gradient delta-turbidite system. The favora- 
ble reservoir is located in the delta front and turbidite facies. Hence the prediction accuracy of reservoir distribution is high as the boundary of delta front was delineated base on paleotopography, reservoir architecture, forward modeling analysis, and seismic attributes.

\section{Conflicts of Interest}

The authors declare no conflicts of interest regarding the publication of this paper.

\section{References}

Cui, L., Feng, D., \& Qin, Y. (2013). Paleogeomorphology Reconstruction and Sand Body Distribution of Chang 7 Reservoir in Zhenbei Area, Ordos Basin. Lithologic Reservoirs, 25, 65-69.

Cui, L., Hao, S., \& Wang, C. (2015). Palaeogeomorphology Reconstruction and Sandbody Distribution of the Chang 7-6 Intervals of Triassic Yanchang Formation in Northern Zhenyuan Area, Ordos Basin. Journal of Paleogeography, 17, 805-812.

Deptuck, M. E., Sylvester, Z., Pirmez, C., \& O’Byrne, C. (2007). Migration Aggradation History and 3-D Seismic Geomorphology of Submarine Channels in the Pleistocene Benin-Major Canyon, Western Niger Delta Slope. Marine and Petroleum Geology, 24, 406-433. https://doi.org/10.1016/j.marpetgeo.2007.01.005

Galloway, W. E. (1975). Process Framework for Describing the Morphologic and Stratigraphic Evolution of Deltaic Depositional Systems (pp. 87-98). Houston, TX: Houston Geological Society.

Galloway, W. E., \& Hobday, D. K. (1983). Terrigenous Clastic Depositional Systems: Applications to Petroleum, Coal, and Uranium Exploration. New York: Springer-Verlag. https://doi.org/10.1007/978-1-4684-0170-7

Lemons, D. R., \& Chan, M. A. (1999). Facies Architecture and Sequence Stratigraphy of Fine-Grained Lacustrine Deltas along the Eastern Margin of Late Pleistocene Lake Bonneville, Northern Utah and Southern Idaho. AAPG Bulletin, 83, 635-665.

Lin, C., Zheng, H., \& Ren, J. (2004). The Control of Syndepositional Faulting on the Eogene Sedimentary Basin Fills of the Dongying and Zhanhua Sags, Bohai Bay Basin. Science in China: Series D, 9, 769-782. https://doi.org/10.1360/03yd0203

Plint, A. G., \& Wadsworth, J. A. (2003). Sedimentology and Paleogeomorphology of Four Large Valley Systems Incising Delta Plains, Western Canada Foreland Basin: Implications for Mid-Cretaceous Sea-Level Changes. Sedimentology, 50, 1147-1186. https://doi.org/10.1111/j.1365-3091.2003.00599.x

Posamentier, H. W., \& Allen, G. P. (1993). Variability of the Sequence Stratigraphic Model: Effects of Local Basin Factors. Sedimentary Geology, 86, 91-109. https://doi.org/10.1016/0037-0738(93)90135-R

Posamentier, H. W., \& Kolla, V. (2003). Seismic Geomorphology and Stratigraphy of Depositional Elements in Deep-Water Settings. Journal of Sedimentary Research, 73, 367-388. https://doi.org/10.1306/111302730367

Wang, Y., Jin, W., \& Liu, S. (2003). Genetic Type's Distribution and Exploration Significance of Multistage Slope Breaks in Rift Lacustrine Basin. Oil \& Gas Geology, 24, 199-203.

Wang, Y., Liu, H., \& Li, L. (2002). Types and Distribution Characteristics of Slope Breaks of Large Type down Warped Lake Basins. Earth Science-Journal of China University 
of Geosciences, 27, 683-688.

Zhang, J., Huang, K., \& Liao, X. (2015). Reservoir Prediction and Application of Progradation Reservoir, $\mathrm{E}^{2} \mathrm{~S}_{3}{ }^{\mathrm{M}}$ Southern Bohai Water. Science and Technology and Engineering, 17, 131-136. 